\title{
Рост концентрации носителей заряда в тонких пленках висмута
}

\author{
() Е.В. Демидов, В.М. Грабов, В.А. Комаров, А.В. Суслов, В.А. Герега, А.Н. Крушельницкий \\ Российский государственный педагогический университет им. А.И. Герцена, \\ 191186 Санкт-Петербург, Россия \\ E-mail: demidov_evg@mail.ru
}

Поступила в Редакцию 19 сентября 2021 г.

В окончательной редакции 24 сентября 2021 г.

Принята к публикации 24 сентября 2021 г.

Обсуждаются причины роста концентрации носителей заряда в тонких пленках висмута при уменьшении их толщины. Расчет концентрации произведен на основе измеренных электрических и гальваномагнитных коэффициентов при температуре $77 \mathrm{~K}$ в рамках двухзонного приближения и предположения изотропности длины свободного пробега носителей заряда в плоскости пленки.

Ключевые слова: висмут, тонкая пленка, концентрация носителей заряда, поверхность.

DOI: 10.21883/FTP.2022.02.51952.19

\section{1. Введение}

Повышенный интерес к системам пониженной размерности присутствует уже более 50 лет. Особое место в этих исследованиях занимают полуметаллы и узкозонные полупроводники - материалы с рекордными значениями длины волны де Бройля носителей заряда, которая характеризует возможность наблюдения квантовых эффектов в твердых телах.

Типичным и наиболее исследованным представителем данного класса материалов является висмут, в котором за последние десятилетия теоретически предсказан и экспериментально обнаружен целый ряд когерентных эффектов. Однако не все теоретические предсказания в этой области нашли надежное экспериментальное подтверждение.

В работах [1-3] теоретически предсказано, что благодаря квантовому размерному эффекту в кристаллах висмута должен наблюдаться переход полуметалл-полупроводник при размерах образцов порядка длины волны де Бройля носителей заряда.

За последние несколько десятков лет были предприняты неоднократные попытки экспериментально установить переход полуметалл-полупроводник в тонких пленках и нитях висмута [4-6]. Однако несмотря на значительные усилия в этом направлении экспериментальные результаты и их интерпретация остаются неоднозначными. Так, например, в работах $[7,8]$ сообщается не об уменьшении, а о росте концентрации носителей заряда с уменьшением толщины пленок висмута.

В данной работе предпринята попытка установить причины данного противоречия в информации о свойствах тонких пленок висмута.

\section{2. Методика эксперимента}

Пленки висмута были получены методом термического испарения в вакууме. Для испарения использовался висмут чистотой 99.999\%. В качестве подложки использована слюда (мусковит) марки СОВ (толщина пластин 0.005-0.04 мм).

Для получения пленок толщиной 150 нм и менее использовалось электронно-лучевое испарение в вакууме $\sim 10^{-6}$ Па при скорости осаждения висмута $0.1 \mathrm{HM} / \mathrm{c}$. Для пленок толщиной 300 нм использовалось термическое испарение в вакууме $\sim 10^{-3}$ Па при скорости осаждения висмута $5 \mathrm{HM} / \mathrm{c}$. Пленки толщиной 150 нм и менее получены при температуре подложки $413 \mathrm{~K}$ и температуре отжига $473 \mathrm{~K}$, время отжига составляло 1 ч. Пленки толщиной 300 нм получены при различных температурах подложки от 353 до $473 \mathrm{~K}$ с отжигом и без него, время отжига составляло 30 мин. Для получения монокристаллической пленки данной толщины использовалась зонная перекристаллизация под защитным покрытием [9]. В случае использования отжига полученные пленки отжигались без нарушения вакуума сразу после получения пленки.

Контроль толщины пленок толщиной 150 нм и менее проводился методом атомно-силовой микроскопии в контактном режиме по специально разработанной методике, с использованием избирательного химического травления границ кристаллитов [10]. Контроль толщины пленок толщиной 300 нм проводился на интерферометре Линника. Погрешность определения толщины пленок указанными методами не превышала 10\%.

Контроль кристаллической структуры пленок осуществлялся на рентгеновском дифрактометре „ДРОН-7“6 фирмы „Буревестник“.

Определение размеров кристаллитов проводилось на сканирующем зондовом микроскопе Solver-P47 Pro фирмы NT-MDT с использованием избирательного химического травления [11] или декорирования с помощью естественного оксидирования [12]. Размер кристаллитов определен с точностью $\sim 10 \%$.

Для исследования электрических свойств пленок висмута термическим напылением формировались контактные площадки из меди или манганина. 
Исследование электрических и гальваномагнитных свойств (удельное сопротивление, магнетосопротивление, коэффициент Холла) производилось по классической методике на постоянном токе и постоянном магнитном поле при температуре $77 \mathrm{~K}$.

Погрешность измерения удельного сопротивления и коэффициента Холла 10\%. Относительное магнетосопротивление измерялось с погрешностью $5 \%$.

В работе использовалось научное оборудование междисциплинарного ресурсного центра коллективного пользования „Современные физико-химические методы формирования и исследования материалов для нужд промышленности, науки и образования“ (РГПУ им. А.И. Герцена).

\section{3. Экспериментальные результаты и обсуждение}

\section{1. Структура тонких пленок}

Исследование структуры полученных пленок методами рентгеноструктурного анализа показало, что пленки висмута толщиной $>25$ нм имеют кристаллографическую ориентацию, соответствующую ориентации плоскости (111) параллельно плоскости подложки. Положение дифракционных максимумов на дифрактограммах от пленок висмута совпадает с положением максимумов от плоскости (111) монокристалла висмута. Это указывает на равенство межплоскостных расстояний в пленке висмута и монокристалле висмута.

Для примера на рис. 1 представлены дифрактограммы, полученные по схеме $\theta-2 \theta$, для пленки висмута толщиной 27 нм на слюде, для слюды и монокристалла висмута. Отмечены максимумы, принадлежащие висмуту.

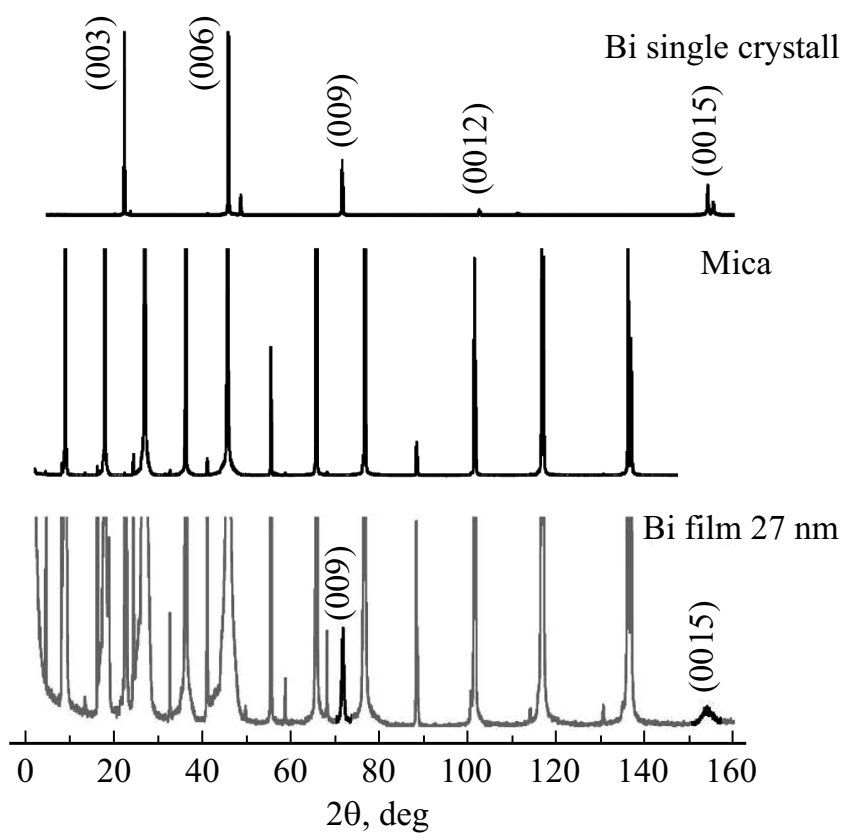

Рис. 1. Дифрактограммы монокристалла висмута, слюды и пленки висмута.
Положение максимумов пленочного кристалла висмута и монокристалла полностью совпадают. В рамках данной работы для пленок висмута толщиной < 25 нм не удалось получить хорошие дифракционные картины. Возможно, это связано с малым соотношением сигнал шум или с модификацией структуры для пленок таких толщин.

В работе [11] показано, что на поверхности пленок висмута на слюде, полученных методом термического испарения в вакууме, имеются хиллоки. Концентрация данных образований быстро падает с повышением температуры подложки в процессе получения пленок [13]. В данной работе методом атомно-силовой микроскопии также обнаружены данные структуры в пленках висмута. Определение размеров блоков осуществлялось с учетом концентрации и размеров хиллоков по методике, описанной в работах $[14,15]$.

\section{2. Методика определения концентрации носителей заряда в пленках висмута}

Основным признаком перехода висмута из полуметаллического состояния в полупроводниковое при уменьшении толщины пленки является уменьшение концентрации носителей заряда. Определение концентрации носителей заряда в пленках висмута производилось на основе измеренных коэффициентов переноса: удельное сопротивление $(\rho)$, коэффициент Холла $(R)$ и магнетосопротивление $\left(\frac{\Delta \rho}{\rho B^{2}}\right)$ в слабом магнитном поле.

Расчет производился в рамках двухзонного приближения, в предположении равенства концентрации электронов и дырок и слабого магнитного поля. В данном приближении, с учетом кристаллографической ориентации пленок, измеряемые в них удельное сопротивление, магнетосопротивление и коэффициент Холла соответствуют компонентам тензоров гальваномагнитных коэффициентов монокристалла висмута $\rho_{11}, \rho_{11,33}, R_{12,3}$. Индексы указывают на обозначение осей в кристаллографической системе координат (ось 1 параллельна оси симметрии кристалла $\mathrm{C}_{2}$, ось 3 параллельна оси симметрии $\mathrm{C}_{3}$, а ось 2 перпендикулярна $\mathrm{C}_{2}$ и $\mathrm{C}_{3}$ ). Коэффициенты переноса $\rho_{11}, \rho_{11,33}, R_{12,3}$ в слабом поперечном магнитном поле обычно выражаются через элементарный заряд $e$, концентрацию $n$ и компоненты подвижностей носителей заряда в системах координат, связанных с осями симметрии электронных и дырочного эллипсоидов $u_{1}^{-}, u_{2}^{-}, u_{1}^{+}=u_{2}^{-}=u^{+}$:

$$
\begin{gathered}
\sigma=\frac{1}{\rho}=\sigma_{11}=-e n\left[\frac{1}{2}\left(u_{1}^{-}+u_{2}^{-}\right)+u^{+}\right] \\
R=R_{12,3}=\frac{e n}{\sigma_{11}^{2}}\left[u_{1}^{-} u_{2}^{-}-\left(u^{+}\right)^{2}\right] \\
\frac{\Delta \rho}{B^{2}}=\rho_{11,33}=-\rho_{11}^{2}\left[e n u^{+3}+\frac{1}{2} e n u_{1}^{-} u_{2}^{-}\left(u_{1}^{-}+u_{2}^{-}\right)\right] \\
-\sigma_{11}\left(R_{12,3}\right)^{2} .
\end{gathered}
$$


Энергия Ферми и составляющие тензора подвижности и эффективных масс электронов по главным осям поверхности Ферми монокристалла висмута при температуре $77 \mathrm{~K}$

\begin{tabular}{c|c|c|c|c}
\hline Ось & $u, \mathrm{~m}^{2} / \mathrm{B} \cdot \mathrm{c}$ & $E_{\mathrm{F}}$, мэB & $m^{*}$ & $L$, МКм \\
\hline 1 & 85.19 & 14.4 & $0.006 \cdot m_{0}$ & 1.90 \\
2 & 4.19 & 14.4 & $1.27 \cdot m_{0}$ & 1.35
\end{tabular}

Примечание. $m_{0}$ - масса свободного электрона.

При анализе явлений переноса в высокосовершенных массивных кристаллах висмута часто используют приближение изотропности времени релаксации. В высокодефектных образцах более применимо приближение изотропности длины свободного пробега [16,17], поэтому в случае пленок при толщинах много меньше длины свободного пробега электронов в массивном кристалле возможно применение приближения изотропности длины свободного пробега электронов $(L)$ в плоскости подложки $\left(L_{1}=L_{2}\right)$.

Оценим длину свободного пробега электронов в висмуте в плоскости (111) при температуре $77 \mathrm{~K}$ в массивном монокристалле, т. е. обусловленную рассеянием на фононах:

$$
L=\frac{1}{|e|} u \sqrt{2 E_{\mathrm{F}} m^{*}},
$$

где $u$ - подвижность, $E_{\mathrm{F}}-$ энергия Ферми, $m^{*}-$ эффективная масса.

Для расчета были взяты данные из работы [18] для температуры $77 \mathrm{~K}$, представленные в таблице.

Результаты расчета представлены в последнем столбце таблицы.

Таким образом, длины свободного пробега электронов в висмуте в плоскости (111), обусловленные рассеянием на фононах при температуре $77 \mathrm{~K}$, составляют > 1 мкм, в связи с этим в случае преимущественно диффузного рассеяния носителей заряда поверхностью даже для пленок толщиной 300 нм можно использовать приближение изотропности длины свободного пробега.

В этом случае для пленки $L_{1}=L_{2}$ и соответственно для пленки висмута

$$
\frac{u_{1}^{-}}{u_{2}^{-}}=\sqrt{\frac{m_{2}^{*}}{m_{1}^{*}}} \approx 14.5 .
$$

Таким образом, с помощью численного решения системы уравнений 1-3 и 6, используя значения измеренных коэффициентов переноса, были рассчитаны концентрации и подвижности в полученных пленках висмута.

В связи с использованием в работе достаточно тонких пленок, в которых реализуется размерное квантование и возрастает роль поверхностной электронной структуры, приближение равенства концентрации электронов и дырок может нарушаться. В связи с этим будем использовать данное приближение как гипотезу, при этом оценивая возможность его применения на основе полученных результатов.

\section{3. Влияние размеров блоков на концентрацию и подвижность носителей заряда в пленках висмута}

В отдельных работах сообщается, что причиной роста концентрации носителей заряда в тонких пленках висмута может быть дополнительная концентрация, обусловленная наличием свободной поверхности $[4,19,20]$. Это вполне разумное предположение, так как данная ситуация достаточно часто встречается в полупроводниках. Так как пленки висмута в большинстве случаев блочные, дополнительная концентрация носителей заряда может формироваться и вследствие наличия границ кристаллитов.

Тогда концентрация в пленке будет определяться выражением:

$$
\begin{aligned}
n_{\text {film }}= & n_{\text {bulk }}+n_{\text {surface }} \cdot d_{\text {surface }} \cdot \frac{1}{h} \\
& +n_{\text {crystal bounder }} \cdot d_{\text {crystal bounder }} \cdot \frac{1}{G},
\end{aligned}
$$

где $n_{\text {bulk }}$ - концентрация в массивном монокристалле висмута, $n_{\text {surface }}$ - дополнительная концентрация носителей заряда вследствие наличия свободной поверхности, $d_{\text {surface }}$ - толщина поверхностного слоя, в котором формируется дополнительная концентрация носителей заряда, $n_{\text {crystal bounder }}$ - дополнительная концентрация носителей заряда вследствие наличия границ кристаллитов, $d_{\text {crystal bounder }}$ - толщина границ кристаллитов, в которых формируется дополнительная концентрация носителей заряда, $h-$ толщина пленки, $G-$ размер кристаллитов.

Таким образом, в случае формирования дополнительной концентрации носителей заряда на границах кристаллитов в пленке висмута для пленок фиксированной толщины, но имеющих различные размеры кристаллитов, ее значения будут линеаризовываться в координатах $n_{\text {film }}$ от $1 / G$, а тангенс угла наклона прямой будет равен $n_{\text {crystal bounder }} \cdot d_{\text {crystal bounder. Аналогичная ситуация }}$ будет и в случае фиксированного значения размеров кристаллитов для пленок переменной толщины. В этом случае значения концентрации носителей заряда будут линеаризовываться в координатах $n_{\text {film }}$ от $1 / h$.

По аналогии с выражением (6) в случае независимости вкладов различных механизмов рассеяния в ограничение подвижностей носителей заряда фононами $\left(1 / u_{\text {phon }}\right)$, поверхностью $\left(1 / u_{h}\right)$ и границами кристаллитов $\left(1 / u_{G}\right)$ в соответствии с правилом Маттиссена можно записать

$$
\frac{1}{u_{\text {film }}}=\frac{1}{u_{\text {phonons }}}+a \cdot \frac{1}{h}+b \cdot \frac{1}{G},
$$

где $u-u_{1}^{-}, u_{2}^{-}$или $u^{+}, a-$ коэффициент, характеризующий рассеяние носителей заряда поверхностью, $b-$ коэффициент, характеризующий рассеяние носителей заряда границами кристаллитов. 


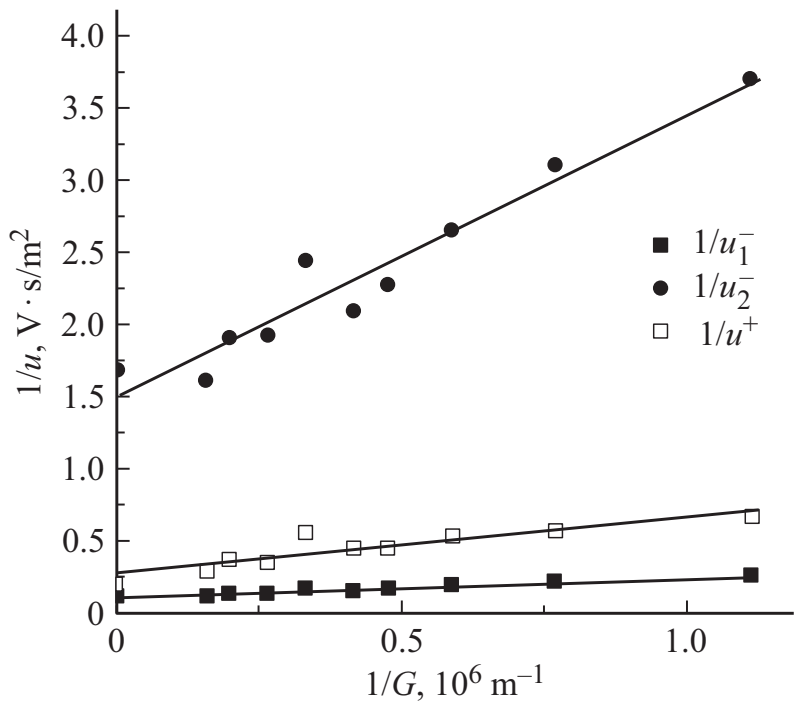

Рис. 2. Зависимость обратных значений подвижности электронов и дырок от $1 / G$ для пленок висмута толщиной 300 нм при температуре $77 \mathrm{~K}$.

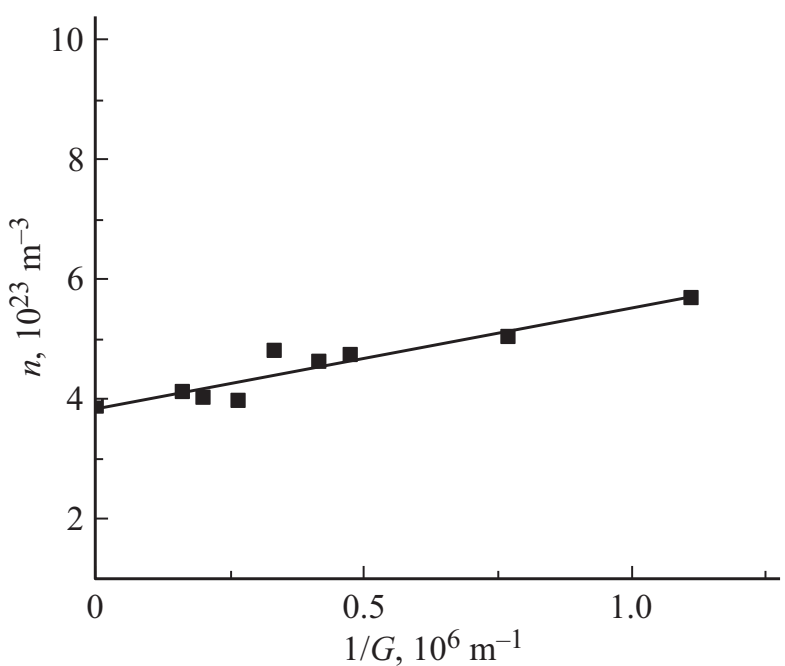

Рис. 3. Зависимость концентрации носителей заряда от $1 / G$ для пленок висмута толщиной 300 нм при температуре $77 \mathrm{~K}$.

Линейный вид зависимостей значений подвижностей в координатах $1 / u$ от $1 / G$ или $1 / h$ в случае фиксированной толщины или размеров кристаллитов может являться критерием справедливости используемых приближений, в том числе предположения равенства концентрации электронов и дырок.

Технологически гораздо более просто изготовить серию пленок с фиксированной толщиной и переменным значением размеров кристаллитов по сравнению с серией пленок с фиксированным размером кристаллитов и переменной толщиной. В связи с этим для экспериментальной проверки выражения (7) была получена серия пленок висмута толщиной 300 нм, имеющих размеры кристаллитов от 0.9 до 6.3 мкм, а также монокристаллическая пленка, полученная зонной перекри- сталлизацией под покрытием. Для получения пленок с различными размерами кристаллитов использовались различные температуры подложки в диапазоне от 353 до $473 \mathrm{~K}$ и наличие или отсутствие отжига в процессе получения пленки. В полученных пленках измерены удельное сопротивление, магнетосопротивление и коэффициент Холла в слабых магнитных полях и рассчитаны концентрации и подвижности носителей заряда. Во всех формулах, отражающих полученные линейные зависимости концентрации и подвижностей носителей заряда, подразумевается использование международной системы единиц СИ.

На рис. 2 приведены зависимости подвижности электронов и дырок в координатах $1 / u$ от $1 / G$. Как и в более ранних работах, например [14], с учетом небольшого статистического разброса эти зависимости хорошо линеаризуются, что указывает на справедливость используемых для расчета предположений, в том числе предположения равенства концентраций носителей заряда для пленок толщиной 300 нм.

Уравнения аппроксимирующих прямых, представленных на рис. 2, имеют следующий вид:

$$
\begin{aligned}
& \frac{1}{u_{1}^{-}}=0.1+1.36 \cdot 10^{-7} \frac{1}{G}, \\
& \frac{1}{u_{2}^{-}}=1.49+1.97 \cdot 10^{-6} \frac{1}{G}, \\
& \frac{1}{u^{+}}=0.27+3.86 \cdot 10^{-7} \frac{1}{G} .
\end{aligned}
$$

На рис. 3 приведены зависимости концентрации носителей заряда в координатах $n$ от $1 / G$. Статистический разброс значения концентраций более выражен по сравнению подвижностями. Несмотря на это хорошо прослеживается увеличение концентрации носителей заряда при уменьшении размеров кристаллитов. Уравнение аппроксимирующей прямой, представленной на рис. 3 имеет следующий вид:

$$
n_{\text {film }}=3.8 \cdot 10^{23}+1.7 \cdot 10^{17} \frac{1}{G} .
$$

Сопоставляя выражения (6) и (11), имеем $n_{\text {crystal bounder }} \cdot d_{\text {crystal bounder }}=1.7 \cdot 10^{17} \mathrm{M}^{-2}, \quad$ стандартная ошибка составляет $0.2 \cdot 10^{17} \mathrm{M}^{-2}$.

\section{4. Влияние толщины пленки на концентрацию и подвижность носителей заряда в пленках висмута}

Для определения влияния поверхности на концентрацию носителей заряда в пленках висмута была получена серия пленок висмута толщиной от 15 до 300 нм. На основе измеренных коэффициентов переноса рассчитаны подвижности и концентрации носителей заряда. Также использовались данные о подвижности и концентрации носителей заряда в монокристалле висмута из работы [18] с учетом уменьшения концентрации носителей 

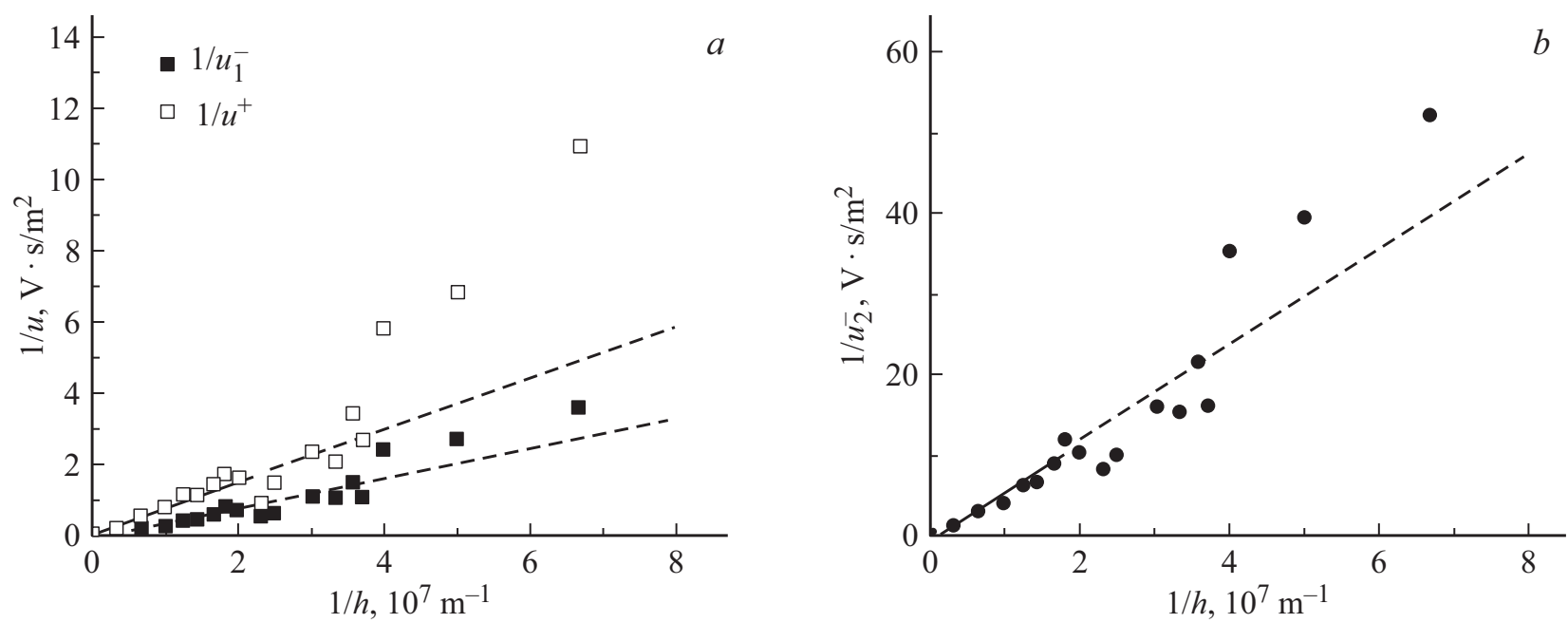

Рис. 4. Зависимость обратных значений подвижности электронов и дырок от $1 / h$, обусловленных рассеянием фононами и поверхностью при температуре $77 \mathrm{~K}$.

в висмуте в связи с его механической деформацией вследствие несоответствия коэффициента температурного расширения висмута и слюды [21].

На рис. 4 приведены зависимости подвижности электронов и дырок в координатах $1 / u$ от $1 / h$, обусловленные рассеянием фононами и поверхностью. Исключение из подвижностей рассеяния, обусловленного границами блоков, осуществлялось с использованием полученных в предыдущем разделе коэффициентов $b$ и измеренными размерами кристаллитов в пленках.

На полученных зависимостях для электронов в середине исследованного интервала толщин хорошо прослеживается уменьшение обратных подвижностей относительно линейной зависимости, характерной для более толстых пленок, что обусловлено проявлением квантового размерного эффекта [22], который приводит к росту энергии Ферми [23] и соответственно к уменьшению обратной подвижности электронов. В пленках толщиной $<25$ нм значения обратных подвижностей для электронов и дырок несколько выше по сравнению с указанной линейной зависимостью. Причины этого будут обсуждаться после анализа концентрации носителей заряда.

Уравнения аппроксимирующих прямых, представленных на рис. 4, имеют следующий вид:

$$
\begin{gathered}
\frac{1}{u_{1}^{-}}=1.17 \cdot 10^{-2}+4.09 \cdot 10^{-8} \frac{1}{h}, \\
\frac{1}{u_{2}^{-}}=0.24+5.91 \cdot 10^{-7} \frac{1}{h}, \\
\frac{1}{u^{+}}=7.47 \cdot 10^{-2}+7.28 \cdot 10^{-8} \frac{1}{h} .
\end{gathered}
$$

На рис. 5 приведены зависимости концентрации носителей заряда от обратной толщины пленки. Так как пленки имели различные размеры кристаллитов в диапазоне от 0.4 до 6.3 мкм, с целью анализа экспериментальных данных в соответствии с выражением (6)

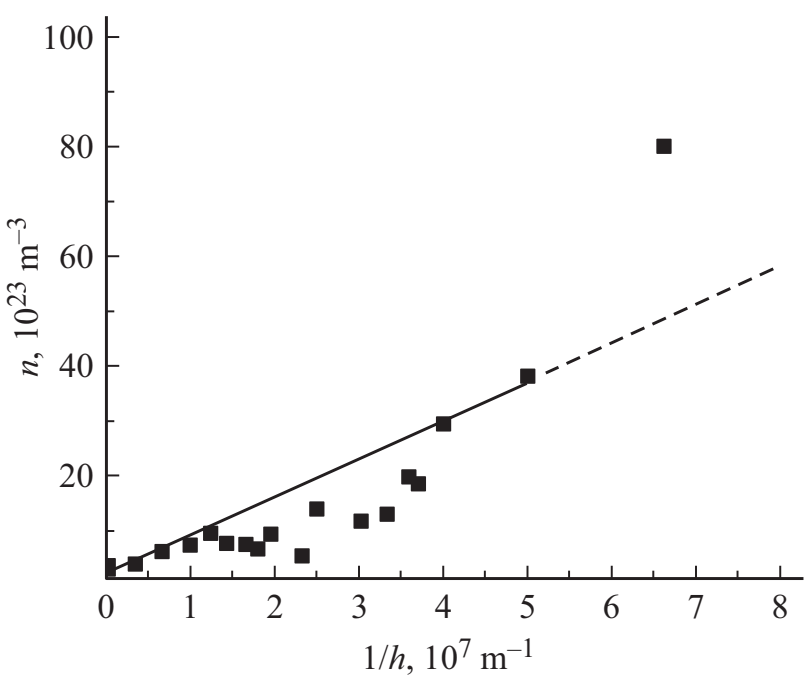

Рис. 5. Зависимость концентрации носителей заряда от $1 / h$ для пленок висмута при температуре $77 \mathrm{~K}$ без дополнительной концентрации носителей заряда вследствие блочной структуры пленок.

из рассчитанных на основе измеренных коэффициентов переноса значений концентраций носителей заряда были исключены концентрации носителей заряда, обусловленные блочной структурой пленки в соответствии с полученным в предыдущем разделе значением $n_{\text {crystal bounder }} \cdot d_{\text {crystal bounder }}$ и фактическим размером кристаллитов в пленке.

С уменьшением толщины пленок наблюдается существенный рост концентрации носителей заряда. На участке, соответствующем пленкам толщиной $>60$ нм, хорошо выполняется выражение (6). Далее, как и в случае подвижности электронов, в середине исследованного интервала толщин хорошо прослеживается уменьшение концентрации носителей заряда относительно линейной 
зависимости, характерной для более толстых пленок, однако значения концентрации для более тонких пленок, кроме пленки толщиной 15 нм, возвращаются на данную прямую, в отличие от подвижности электронов.

Уменьшение концентрации носителей заряда в середине интервала толщин обусловлено проявлением квантового размерного эффекта, который приводит к уменьшению концентрации носителей заряда в пленках полуметаллов [2,23]. Для пленок толщиной 25 нм и менее пленка переходит в ,ультраквантовую область“ с возможным изменением электронного энергетического спектра носителей заряда.

Уравнение аппроксимирующей прямой, представленной на рис. 5, имеет следующий вид:

$$
n_{\text {film }}=3 \cdot 10^{23}+0.7 \cdot 10^{17} \frac{1}{h} .
$$

Сопоставляя выражения (6) и (15), имеем $n_{\text {surface }} \cdot d_{\text {surface }}=0.7 \cdot 10^{17} \mathrm{M}^{-2}, \quad$ стандартная составляет: $0.02 \cdot 10^{17} \mathrm{M}^{-2}$.

Концентрация носителей заряда в пленке толщиной 15 нм существенно выше по сравнению с линейной зависимостью $n(1 / h)$, полученной для пленок большей толщины, что вероятно обусловлено существованием других, по отношению к обсуждаемым в данной статье, механизмов, обеспечивающих рост концентрации носителей заряда.

Вернемся к вопросу о низких значениях подвижности носителей заряда для пленок толщиной 15-25 нм (рис. 4).

Для висмута известно, что в случае рассеяния на фононах при увеличении концентрации носителей заряда пропорционально уменьшается их подвижность [18]. При этом данная закономерность сохраняется при росте концентрации как вследствие повышения температуры, так и вследствие легирования. Можно предположить, что увеличение концентрации вследствие влияния поверхности и границ кристаллитов также будет приводить к уменьшению подвижности носителей заряда. Однако наблюдаемое увеличение концентрации носителей заряда в данных пленках и значения подвижности электронов и дырок при рассеянии их на фононах в массивном монокристалле при $77 \mathrm{~K}$ не дает таких низких значений подвижности, наблюдаемых в данной работе, для пленок толщиной 25-15 нм. Это, вероятно, обусловлено нарушением предположения равенства концентрации электронов и дырок для пленок висмута толщиной $<25$ нм. Низкие значения подвижностей носителей заряда могут быть обусловлены и формированием менее совершенных границ кристаллитов по сравнению с более толстыми пленками. Однако исследования структуры пленок отличий в структуре границ кристаллитов для пленок с толщинами менее и более 25 нм не выявили.

\section{4. Заключение}

В рамках данной работы в пленках висмута при толщинах порядка длины волны де Бройля и существенно меньших ее значений переход полуметалл-полупроводник в электрических и гальваномагнитных явлениях не наблюдался. Наблюдалась обратная ситуация - рост концентрации носителей заряда при уменьшении толщины пленки. Анализ полученных экспериментальных результатов указывает на то, что причиной роста концентрации носителей заряда в пленках висмута при уменьшении толщины является дополнительная концентрация, обусловленная наличием свободной поверхности и границами кристаллитов. При этом квантовый размерный эффект уменьшает концентрацию носителей заряда. Для пленок висмута толщиной $<25$ нм существенное возрастание концентрации носителей заряда, возможно, осуществляется с нарушением равенства концентрации электронов и дырок.

\section{Финансирование работы}

Работа выполнена в рамках государственного задания при финансовой поддержке Министерства просвещения Российской Федерации (проект FSZN-2020-0026).

\section{Конфликт интересов}

Авторы заявляют, что у них нет конфликта интересов.

\section{Список литературы}

[1] В.Н. Луцкий. Письма ЖЭТФ, 2, 391 (1965).

[2] В.Б. Сандомирский. ЖЭТФ, 52, 158 (1967.)

[3] Y.-M. Lin, X. Sun, M.S. Dresselhaus. Phys. Rev. B, 62, 4610 (2000).

[4] P. Hofmann. Progr. Surf. Sci., 81, 191 (2006).

[5] V.P. Duggal, R. Rup. J. Appl. Phys., 40, 492 (1969).

[6] C.A. Hoffman, J.R. Meyer, F.J. Bartoli, A. Di Venere, X.J. Yi, C.L. Hou, H.C. Wang, J.B. Ketterson, G.K. Wong. Phys. Rev. B, 48, 11431 (1993).

[7] Е.В. Демидов, В.М. Грабов, В.А. Комаров, Н.С. Каблукова, А.Н. Крушельницкий. ФТТ, 60, 452 (2018).

[8] Ю.Ф. Комник, Е.И. Бухштаб, Ю.В. Никитин, В.В. Андриевский. ЖЭТФ, 60, 669 (1971).

[9] В.М. Грабов, В.А. Комаров, Н.С. Каблукова, Е.В. Демидов, А.Н. Крушельницкий. Письма ЖТФ, 41, 20(2015)

[10] Е.В. Демидов, В.А. Комаров, А.Н. Крушельницкий, А.В. Суслов. ФТП, 51, 877 (2017).

[11] В.М. Грабов, Е.В. Демидов, В.А. Комаров. ФТТ, 50, 1312 (2008).

[12] В.М. Грабов, Е.В. Демидов, В.А. Комаров, М.М. Климантов. ФТТ, 51, 800 (2009).

[13] В.М. Грабов, Е.В. Демидов, В.А. Комаров, М.М. Климантов, Д.Ю. Матвеев, С.В. Слепнев, Е.В. Усынин, Е.Е. Христич, Е.В. Константинов. Изв. Росс. гос. пед. ун-та им. А.И. Герцена, № 95, 105 (2009).

[14] В.М. Грабов, Е.В. Демидов, В.А. Комаров. Поверхность. Рентгеновские, синхротронные и нейтронные исследования, № 2, 81 (2011).

[15] В.М. Грабов, Е.В. Демидов, В.А. Комаров. ФТТ, 52, 1219 (2010).

[16] Дж. Займан. Электроны и фбононы (М., ИИЛ, 1962). 
[17] Ф.Д. Блатт. Теория подвижности электронов в твердых mелах (М., Физматлит, 1963).

[18] В.М. Грабов. Докт. дис. (СПб., РГПУ им А.И. Герцена, 1998).

[19] T. Hirahara, T. Nagao, I. Matsuda, G. Bihlmayer, E.V. Chulkov, Y.M. Koroteev, P.M. Echenique, M. Saito, S. Hasegawa. Phys. Rev. Lett., 97, 146803 (2006).

[20] T. Hirahara, I. Matsuda, S. Yamazaki, N. Miyata, S. Hasegawa, T. Nagao. Appl. Phys. Lett., 91, 202106 (2007).

[21] В.М. Грабов, В.А. Комаров, Н.С. Каблукова. ФТТ, 58, 605 (2016)

[22] Е.В. Демидов, В.М. Грабов, В.А. Комаров, А.Н. Крушельницкий, А.В. Суслов, М.В. Суслов. ФТП, 53, 736 (2019).

[23] Ю.Ф. Комник. Физика металлических пленок (М., Атомиздат, 1979).

Редактор Г.А. Оганесян

\section{The increasing of charge carriers' concentration in thin bismuth films}

E.V. Demidov, V.M. Grabov, V.A. Komarov, A.V. Suslov, V.A. Gerega, A.N. Krushelnitckii

Herzen State Pedagogical University, 191186 St. Petersburg, Russia

Abstract The reasons for increasing the charge carriers' concentration in thin bismuth films are discussed. The concentration was calculated on the basis of the measured electrical and galvanomagnetic coefficients at the temperature $77 \mathrm{~K}$ under the two-band approximation and the assumption that the charge carriers' free path in the film is isotropic. 